\title{
日本直腸肛門病學 會雜誌
}

\author{
第一卷 第一號
}

（昭和十五年七月一日）

[學術講演〕

面.腸ノ血管二就テ

東京慈恵會罡科大學々長

籍罢博士金杉英五郎

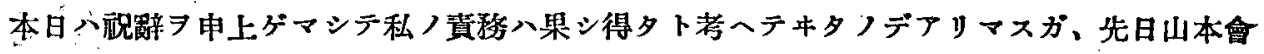

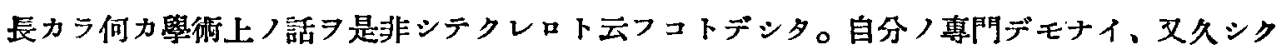
學問ノ方二蜼レテサル人間デアリマスノデ、到底皆樣ノ御滿足ニナル樣ナ問題ヨ發見スル事 八難カシイノデアリマス。3、私ガ誇ル二足ルト考へテキル事い、今日＝至りマシテモ㱠ト

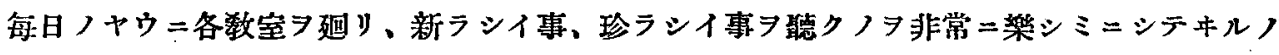
デアリマス。珍ラシイト感ジマスト或部問二於テ八数日間研究モ故シテ居リ、ソレ故二全然 學問ア寨テ、シマツティルノデモナイ。今日ドンナ事ヨオ話シテョイカトイフ事ヨ此間考

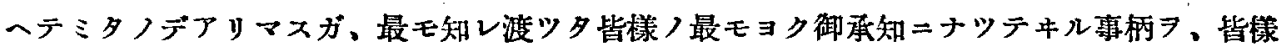

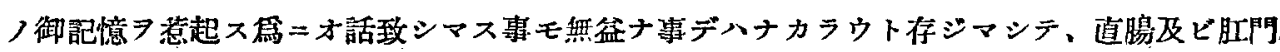
ノ血管系統卜直腸及ビ肛門ノ疾病二就テ、極メテ簡短二才話政サウト思ヒマス。此處二標本 ヨ持ツテ参リマシタ。之八私ノ大學ノ解剖ノ中村教授獨特ノ染色法デ、之八他虑デ八何處二

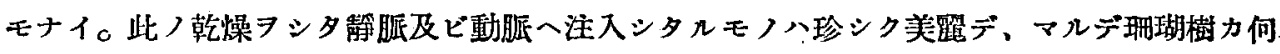
カノ椂二出ティル。大體之ヨオ目ニカケタイノガ目的デアリマス。ソコデ先ヅ直腸〉血管系 統二就テ極メテォ制リニナリ易イ樣ニオ話ヨシテミタイト思フ。

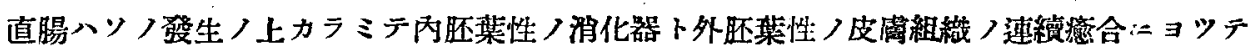
成立シタル部分デアリマスカラ、其つ血管系統モ他ノ消化器官ノ場合つ如ク單純デナイ矛八 御承知ノ通りデアリマス。

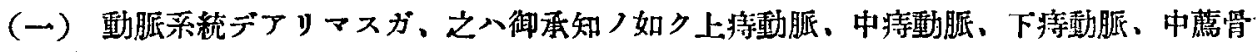
動脈ガアリ、第一、下痔動脈八申迄モナク腹部大動脈系デアリマス。中侍動脈八下部動脈系 
デフリ、下痔動脈モ下腹部動脈系デアリマス。中薦骨動脈ノ分䏢八腹部大動胒系デアリマ $x_{0}$

第一ノ上痔動脈ハ、ソノ大サガ 3 乃至 $4 \mathrm{~mm}$ ノ著明ナ動脈デアツテ後二標本ヨ御覽ニナレ バ直グニ制リマス。之八何處カラ分レデルカト云フト、下腸間膜動脈デ分レテキル。而シ

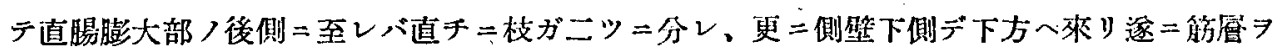

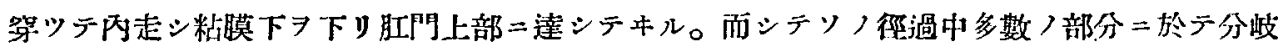
シ互二物今シ緻密子網羅シ作ツテキル。後デ御覽願ヒマス。

第二ノ中痔動脈八其，大サガ 1 万至 $1,5 \mathrm{~mm}$ ノ小サイ動脈デアッテ、骨盤內二於テ下腹部

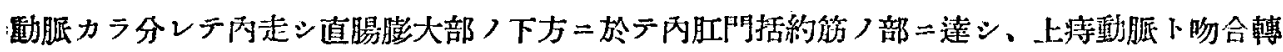

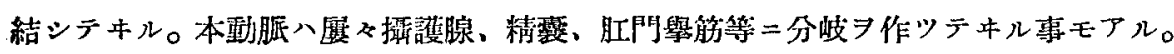

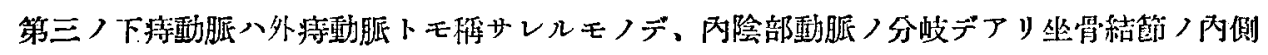

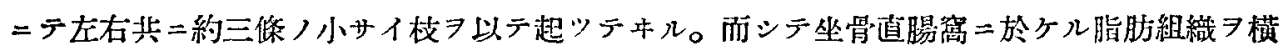

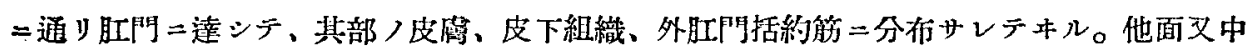

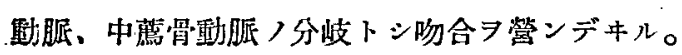

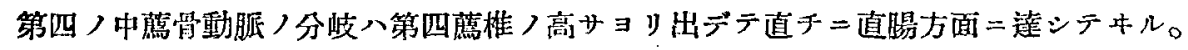
之ヨ要スル二直晹二於ヶル動胍ノ分岐八上痔動脈ガソノ主要ナモノデアツテ、他ノ中痔動

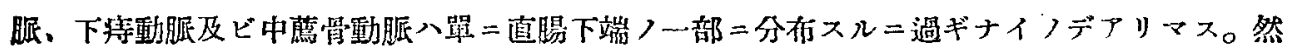

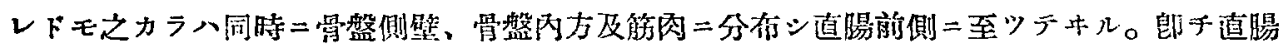

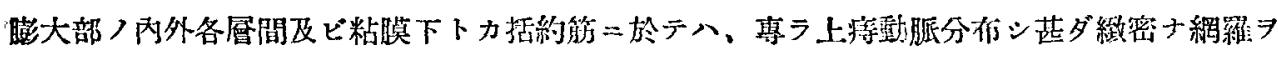

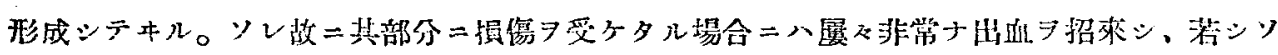

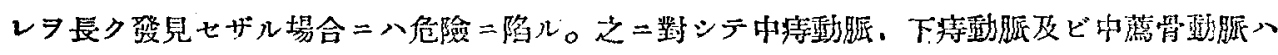

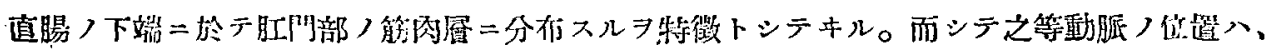

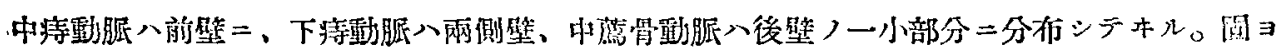

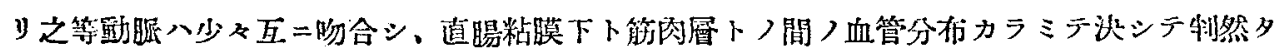
ル竟がアルワケデハアリマセン。各タ動脈互二連絬シデルカラ、結局腹部大動脈ヨリ來ル

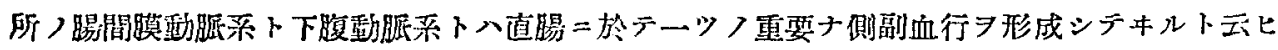
得ルノデフリマス。以上動脈ノ直腸及ビ肛門部ニ於ケル大體ノ分有デアリマス。

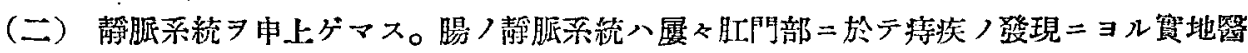

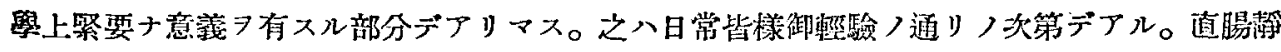

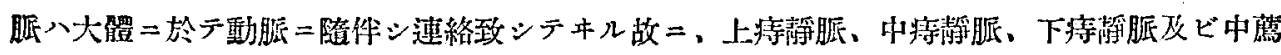

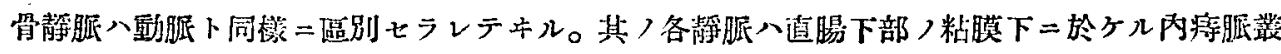
ニ起源シテ居リマス。 


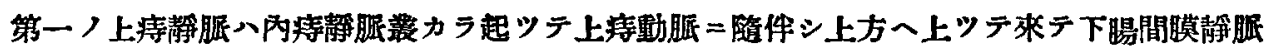

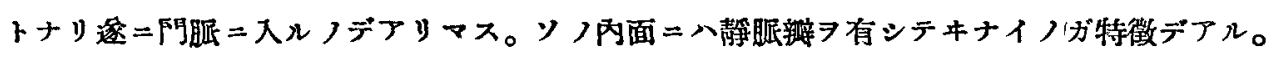

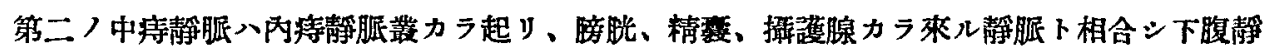
眽へスリマス。

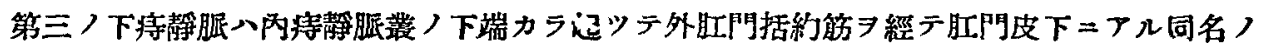
動脈卜相化ツテ坐骨直腸煘

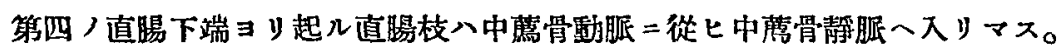

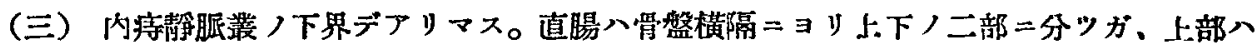
值陽骨繁部下云ヒ、ソレョリ下部八直晹肛門部下ト申ス事八御承知ノ通りデアリマス。而シ

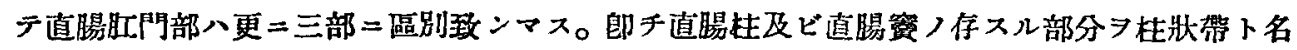
附ケマス。ソノ下方カラ現ハレティル所ヨ中間帶ト云七、更二最下部ヨ皮感ト云つ。而ンテ

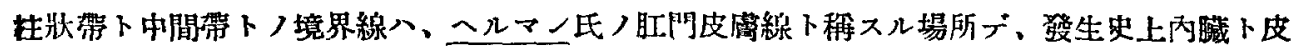

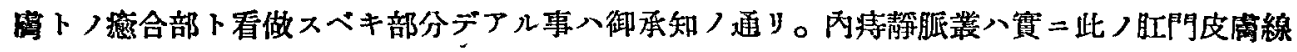

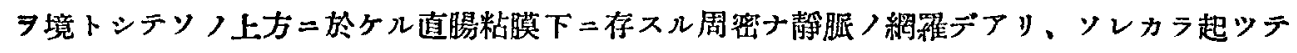

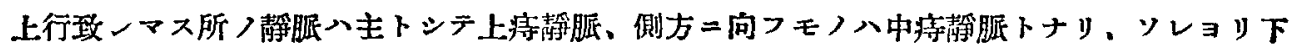

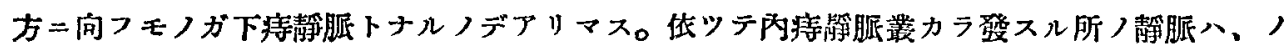
ノ大部分八上痔静脈 $コ$ 通ン門脈二入ツテ之

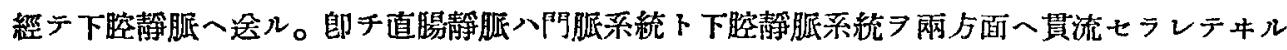

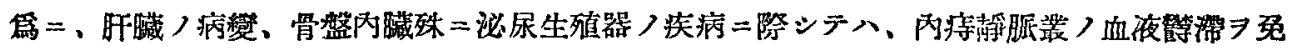

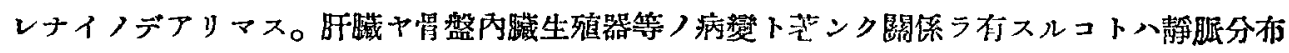
ノ㓠態カラミテモ分りマス。

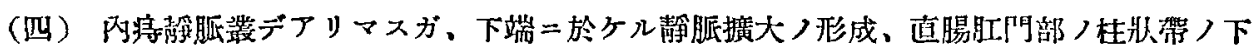

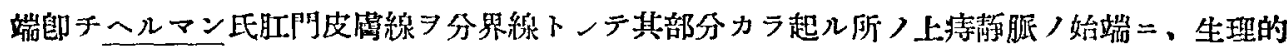

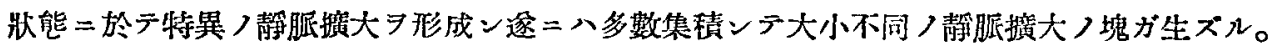

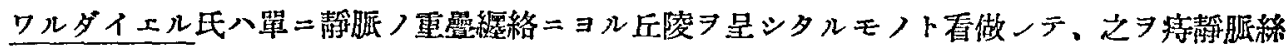

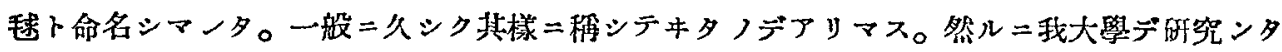

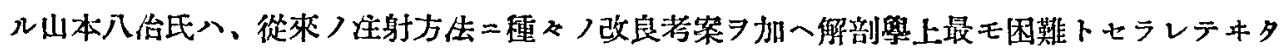

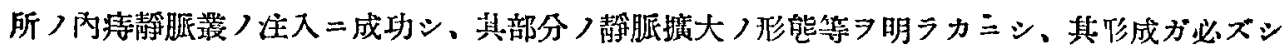

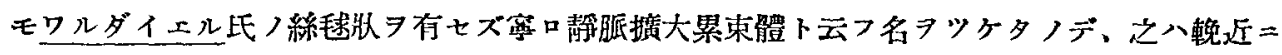

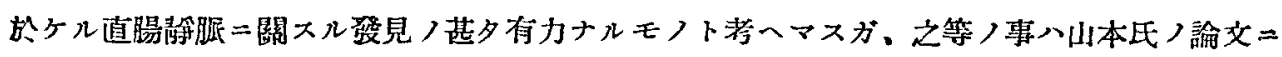
ヨリ私ハ見タノデアリマス。ソノ發現時期並二形態七、山本氏八悉ノク研究ンテ居ラレマス。 此，靜脄掂大八初生兒二於テハ未ダ出ナイガ、一年一ケ月二及ンデ始メテ認メ、三年以後= 
至ルト每常存在スル。其大サ八初八粟粘大乃至米粒大デ年ト共二堭大增殖シ成人二至ルト秦

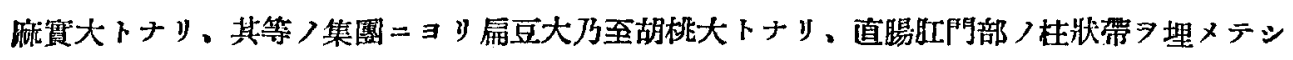
マフ程大キクナルガ、此ノ大キクナツタ事ガ痔核ト云フモノ、起ル所以デフリ、動脈系及ビ

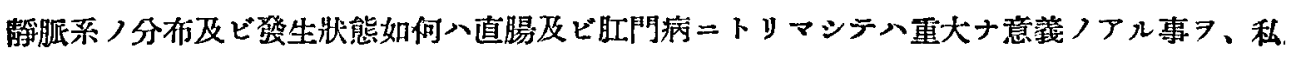

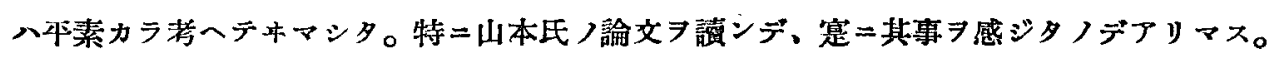

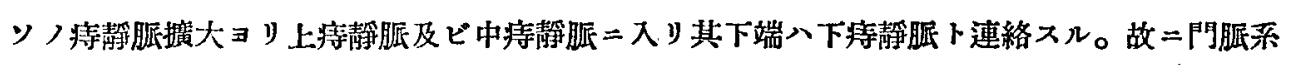
統卜右ノ静脈系統卜ハ之等靜眼擴大二於テ共通致スモノト認メテ差芰ナイト思フノデアリ マス。

要スル二直腸肛門病專問家ノ最モカラスレテ研究スベキハ、直晹及ビ肍門部ノ動脈及ビ静

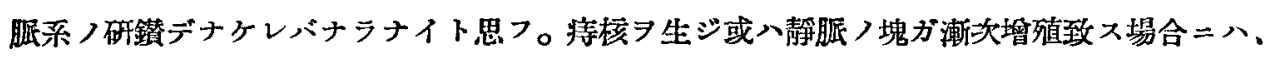
從ツテ粘膜モ著シク肥大シ恐ルベキ将核习生ズル二至ルべキ事八申迄モナイ。ソレ故二努啨 スル場合、例人バ久シイ便秘或八硬便等ノ場合二、著シク靜胍つ膨大 ノアル肝臟及ビ骨盤內獩等ノ疾患ノ第二、肛門及ビ直腸部ノ疾患ヨ起ス事入當然ノ事デアリ

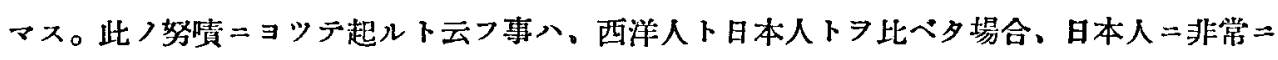
癄疾ノ多イ事ニョツテモ楛へラレル事デ、簡單二申上ゲマスレバ便器＝關係ガアリ、日本， 便器デハ便秘等ヨシデタ孝ニハ非常ナ努嘖ヨ要シマス。ガ酉洋ノ便器デアリマスト支柱ガ

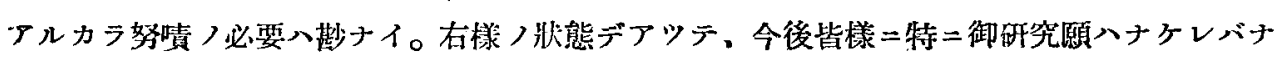

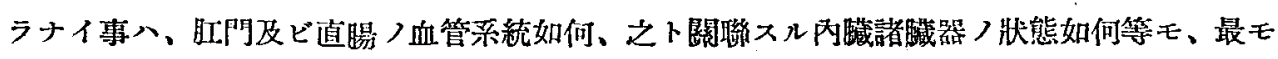
必要ナ事デアラウト思ヒマス。其等二就テ些力經驗シタ事ヨオ話致シタイト思ヒマスガ、本

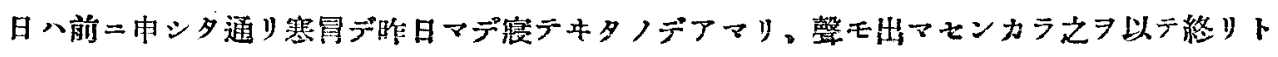
致シマス。 


\title{
Zeitschrift
}

der

\section{Japanischen Proktologischen Gesellschaft}

Band I, Nr. 1, 1. Juni 1940

Kurzer Auszüger aus den Originalmitteilungen

\section{Über die Blutgefässysteme des Rectum.}

\author{
Von Prof. Dr. Eigoro Kanasugi, Rektor der \\ Tokyo Jikeikai Medizinische Akademie
}

(Ein Vortrag, gehalten beì der Eröffnungsfeierlichkeit zur Gründung der Japanischen Proktologischen Gesellschaft.)

Die Arteria haemorrhoidalis superior (A. rectalis cranialis) ist ein Endast der Arteria mesenterica inferior (A. mesenterica caudalis); sie ist im Durchimesser 3 bis $4 \mathrm{~mm}$ gross und die grösste Rectum-Arterie. Sie teilt sich in der Nähe der Ampulla recti in zwei Ästchen. Diese laufen die untere Seite der lateralen Wand der Ampulla recti abwärts weiter, setzen dann die Muskelschicht des Rectum durchbohrend unter der Schleimhaut den Lauf fort und erreichen schliesslich den oberen Teil des Anus. Sie teilen sich im Laufe in viele feine Ästchen, die miteinander anastomosierend ein dichtes Netz bilden.

Die Arteria haemorrhoidalis media (A. rectalis caudalis) ist eine kleine Schlagader mit einem Durchmesser von 1-1.5mm. Dieseibe entspringt im Becken entweder direkt aus der Arteria hypogastrica oder aus einem Zweig der Arteria hypogastrica und läuft im Innern, um dann unterhalb der Ampulla recti den Musculus sphincter ani internus zu erreichen und mit der Arteria haemorrhoidalis superior $z u$ anastomosieren. Sie sendet manchmal Zweige beim Weibe zur Vagina uud beim Manne zur Prostata, zur Vesicula seminalis und zum Musculus levator ani.

De Arteria haemorhoidalis inferior heisst im anderen Namen auch Arteria haemorrhoidalis externa. Dieselbe ist ein Abzweig der Arteria pudenda interna. Sie sind im Ursprunge etwa c'rei kleine Ästchen. Und sie läuft quer durch das Fettgewebe in der Foss 2 ischiorectalis und erreicht den After, um Haut, sublutanes Gewebe und Muskulus sphincter ani externus in dieser Gegend zu versorgen. Anderseits anastomosiert sie auch mit den Abzweigen der Arteria haemorrhoidalis media und der Arteria sacralis media.

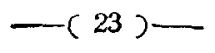


Ein Ästchen, das aus der Arteria sacralis media entspringt, läuft von der Höhe der 4. Kreuzwirbel gleich dem Rectum zu und anastomosiert mit jeder A teria haemorrhcdalis.

Kurz, die hauptsächliche Schlagader im Rectum ist die'Arteria haemorrhoidalis superior, während die Arteria haemorrhoidalis media, die Arteria haemorrhoidalis inferior und die Arteria sacralis media nur einen Teil des unteren Endes des Rectum versorgen. Da die Arteria haemorrhoidalis superior jede äussere und innere Schicht der Ampulla recti und den Musculus sphincter versorgt und ein sehr dichtes Netz bildet, so führt die Verletzung derselben oft eine starke Verblutung herbei. Wenn diese Verletzung lange nicht entdeckt wird, so wird es" sehr gefährlich. Was die Lage dieser Arterien batrifft, so versorgt die Arteria haemorrhoidalis media die Vorderwand des Rectum, die Arteria haemorrhoidalis inferior die beiden Seitenwände desselben und die Arteria sacralis media einen kleinen Teil der Hinterwand desselben. Aber es gibt keine feste Begrenzung zwischen ihnen.

Die Vena des Rectum begleitet im wesentlichen die Schlagader und untersche:det sich in die Vena haemorrhoidalis superior, die Vena haemorrhoidalis media, die Vena haemorrhoidalis inferior und die Vena sacralis media. Und alle diesen Venae haemorrhoidales entspringen aus dem Plexus venosus haemorrhoidalis internus (Plexus rectalis internus).

Die Vena haemorrhoidalis superior (V. rectalis cranialis) entspringt aus dem Plexus venosus haemorrhoidalis internus und zieht in Begleitung der Arteria haemorrhoidalis superior aufwärts steigend zur Vena mesenterica inferior (V. mesenterica caudalis), um schliesslich in die Vena portae einzutreten. Ihr Charakteristikum besteht darin, dass sie mit keiner Venenklappe versehen ist.

Die Vena haemorrhoidalis media (V. rectalis caudalis) entspringt aus dem Plexus venosu; haemorrhoidalis internus und fliesst mit den Venen, die von der Blase, der Vesicula seminalis und der Prostata kommen, zusammen, um schliesslich in die Vena hypogastrica einzutreten. Die Vena haemorrhoidalis inferior entspringt aus dem unteren Ende des Plexus venosus haemorrhoidalis internus und fliesst durch den Musculus sphincter ani externus entlang der gleichnamige. Arte ia unter der Afterhaut und tritt dann quer durch die Fossa ischiorectalis in die Vena pudenda interna. Das Venenästchen der Vena sacralis media entspringt aus dem unteren Ende des Rectum. Da die Venen des Rectum zu den be:den Systemen der Vena portae und der Vena cava inferior fliessen, so ist es unvermeidlich, dass bei der pathologischen Veränderung der Leber und des Beckene ngeweides, insbesordere des urozenitalen Organes die Blutstauung im plexus venosus haemorrhoidalis internus verursucht wird.

Am Anfangsende der Vena haemorrhoidalis superior, die vom unteren Ende der Zona columnalis in der Pars analis recti, der Herrmannschen Linea anacutanea (Herrmann), als Scheidelinie anfängt, bildet sich eine besondere Venendilatation, deren mehrere sich anhäufen, um sich schliesslich zu einem Klumpen von verschieden grossen Venendilatationen zu entwickeln. Diese Bildungen hat Waldeyer Glomera venosa haemorrhoidalis bennant und sie werden seitdem im allgemeinen so benannt. 
In letzter Zeit hat Dr. Hachiji Yamamoto, der im anatomischen Zimmer dieser akademie geforscht hat, die bisherige Injektionsweise verbessert und mit der bisher anatomisch für schwierigst gehaltenen Injektion in den Plexus venosus haemorrhoidalis internus Erfolg gehabt. Er hat ferner über die Form und die Bildungszeit dieser Dilatationen Klarheit verschafft und experimentell nachgewiesen, dass diese Bildungen nicht immer in der Waldemeyerschen Knäuelform erscheinen, vielmehr ein Aggregat von Venendilatationen darstellen. Und für diese Bildungen hat er den Namen Dilatationes venosi haemmorhoidales aggregatae gegeben. Ich halte dies für eine sehr wichtige Entdeckung über die Vena recti in letzter Zeit. Und das habe ich von Dr. Yamamotos Artikel erfahren. Er hat die Entwicklungszeit und Form der Bildungen genau geforscht. Nach seiner Forschung tritt diese Bildung bei Neugeborenen nicht zu Tage, sondern erst ein Jahr und einen Monat später. In der 2. Hälfte des 2. Jahres findet sie sich fast stets. Sie ist anfangs kohlenhirsensamengross oder reiskorngross. Im Laufe der Zeit vergrössert und vermehrt sie sich. Bei Erwachsenen wird sie hanfsamengross. Durch das Anhäufen derselben wird sie linsengross oder nussgross, bis in schliesslich so viel wird, dass die Zona columnalis in der Pars analis recti ganz damit ausgefüllt wird. Dieses Anwachsen ist die Ursache, dass die Haemarrhoiden entstehen. Ich denke stets daran, dass die Verteilungy des Arterien- und Venensystems und dessen Entwicklungszustand von grossem Belang sind. Nachdem ich Dr. Yamamotos Artikel gelesen habe, empfinde ich es lebhaft. Was die Spezialisten der Proktologie mit Nachdruck forschen sollen, würde die Forschung über das Arterien- und Venensystem in der Gegend des Rectum und Anus sein müssen. Wenn die Haemorrhoiden entstehen oder sich die Verteilung des Arterien- und Venenkiumpen allmählig vermehren, so hypernisiert die Schleimhaut infolgedessen bedeutend, so dass sich die gefärrichen Haemorrhoiden entwickeln. Das braucht nicht besonders erwähnt $z \mathfrak{u}$ werden. Aus diesem Grunde ist es natürlich, dass das Drücken z. B. bei langdauernder Stuhlverstopfung oder hartem Kot die Erweiterung der Venen, oder wegen der im Zusammenhang damit stehenden Krankheiten der Leber und des Beckeneingeweides verschiedene Krankheiten des Anus und Rectum verursacht. Dass die Haemorrhoiden durch dieses Drücken entstehen, lässt sich an der Tatsache verstehen, dass die Haemorhoiden bei Japanern bedeutend mehr als bei Europäern vorkommen. Sie haben also einen Zussammenhang mit dem Stuhl. Beim japanischen Stuhl brauchen an Stuhlverstopfung Leidende ein dedeutendes Drücken zu machen. Da man beim europäischen Stuhl Unterstützung hat, so ist das Drücken weniger nötig. Was noch in Zukunft der weiteren Forschung aller anwesenden Spezialisten unterliegt, bezieht sich darauf, wie das Adernsystem des Anus und Rectum ist, und wie das Verhältnis der im Zusammenhang mit ihm stehenden Eingeweideorgane ist. Das würde auch sehr wichtig sein. 